\title{
Correlation of biomarkers for parasite burden and immune activation with acute kidney injury in severe falciparum malaria
}

Katherine Plewes ${ }^{1 \dagger}$, Annick A Royakkers ${ }^{2,3 \dagger}$, Josh Hanson ${ }^{1,4}$, Md Mahtab Uddin Hasan ${ }^{5}$, Shamsul Alam, Aniruddha Ghose ${ }^{5}$, Richard J Maude ${ }^{1}$, Pauline M Stassen ${ }^{3}$, Prakaykaew Charunwatthana', Sue J Lee ${ }^{1,6}$, Gareth DH Turner ${ }^{1,6}$, Arjen M Dondorp ${ }^{1,6^{*}}$ and Marcus J Schultz ${ }^{3}$

\begin{abstract}
Background: Acute kidney injury (AKI) complicating severe Plasmodium falciparum malaria occurs in up to $40 \%$ of adult patients. The case fatality rate reaches $75 \%$ in the absence of renal replacement therapy (RRT). The precise pathophysiology of AKI in falciparum malaria remains unclear. Histopathology shows acute tubular necrosis with localization of host monocytes and parasitized red blood cells in the microvasculature. This study explored the relationship of plasma soluble urokinase-type plasminogen activator receptor (suPAR), as a proxy-measure of mononuclear cell activation, and plasma P. falciparum histidine rich protein 2 (PfHRP2), as a measure of sequestered parasite burden, with AKI in severe malaria.

Methods: Admission plasma SUPAR and PAHRP2 concentrations were assessed in Bangladeshi adults with severe falciparum malaria $(n=137)$. Patients were stratified according to AKI severity based on admission creatinine clearance.
\end{abstract}

Results: A total of 106 (77\%) patients had AKl; 32 (23\%), 42 (31\%) and 32 (23\%) were classified into 'mild, 'moderate' and 'severe' AKI groups, respectively. Plasma suPAR and PAHRP2 concentrations increased with AKI severity (test-fortrend $P<0.0001$ ) and correlated with other markers of renal dysfunction. Admission plasma suPAR and PAHRP2 concentrations were higher in patients who later required RRT $(P<0.0001$ and $P=0.0004$, respectively). In a multivariate analysis, both increasing suPAR and PAHRP2 were independently associated with increasing urine neutrophil gelatinase-associated lipocalin concentration, a marker of acute tubular necrosis ( $\beta=16.54$ (95\% Cl 6.3626.71) and $\beta=0.07$ (0.02-0.11), respectively).

Conclusions: Both sequestered parasite burden and immune activation contribute to the pathogenesis of AKI in severe falciparum malaria.

Keywords: Acute kidney injury, Pathophysiology, Falciparum malaria, Soluble urokinase-type plasminogen activator receptor, Histidine rich protein-2

\footnotetext{
* Correspondence: arjen@tropmedres.ac

${ }^{\dagger}$ Equal contributors

${ }^{1}$ Mahidol Oxford Tropical Medicine Research Unit, Faculty of Tropical

Medicine, Mahidol University, Bangkok, Thailand

${ }^{6}$ Centre for Tropical Medicine, Nuffield Department of Medicine, University of

Oxford, Oxford, UK

Full list of author information is available at the end of the article
} 


\section{Background}

Acute kidney injury (AKI) complicating severe falciparum malaria is an independent predictor of death in both children and adults; without renal replacement therapy (RRT) the adult case fatality rate reaches $75 \%$ [1-3]. The incidence of AKI in severe malaria patients varies across studies, but approaches $40 \%$ in adults and $10 \%$ in children under five years old [4]. Both pre-renal (hypovolemia) and intrinsic renal factors can contribute; two thirds of adults present with anuria or oliguria $[2,4]$. Histopathology shows acute tubular necrosis (ATN) hypothesized to be caused by the observed sequestration of parasitized red blood cells (PRBCs) and accumulation of mononuclear cells in both glomerular and peritubular capillaries [5-7]. However, the relative contribution of each of these mechanisms cannot be assessed from postmortem studies.

Plasmodium falciparum histidine-rich protein 2 (PfHRP2) is released in distinct amounts at the moment of schizont rupture and is quantitatively related to parasite density $[8,9]$. The plasma concentration of PfHRP2 estimates total body $P$. falciparum burden, including the sequestered biomass that causes obstructed microcirculatory flow in vital organs. Unlike the peripheral parasitaemia level, plasma PfHRP2 concentration correlates strongly with disease severity and outcome [10-12].

Plasma soluble urokinase-type plasminogen activator receptor (suPAR) reflects the systemic level of cell surface urokinase-type plasminogen activator receptor (UPAR) expression, and has been proposed as a marker of immune activation via modulation of mononuclear cell adhesion and migration [13-15]. Cell-bound UPAR is expressed on several cell types including activated lymphocytes, monocytes, neutrophils, macrophages, vascular endothelial cells, and kidney podocytes [14,15]. In African children with acute malaria, plasma suPAR concentrations are elevated and associated with higher mortality $[16,17]$. suPAR has not been assessed previously in adults with severe falciparum malaria.

Neutrophil gelatinase-associated lipocalin (NGAL) is secreted predominantly in damaged distal tubular renal epithelial cells prior to neutrophil activation, and is an early marker of renal tubular cell damage [18-20]. NGAL concentration is more reliable as a measure of kidney injury than creatinine as it is less dependent on pre-renal factors [18-20]. Upregulation of NGAL in renal tubule cells may be induced by local release of cytokines from monocytes in the microcirculation after ischemic injury [19].

The relationship between plasma suPAR, as a proxymeasure of mononuclear cell immune activation, and plasma PfHRP2, as a measure of sequestered parasite burden, with AKI in adult patients with falciparum malaria was assessed in this study. Severity of kidney dysfunction and damage was measured quantitatively by creatinine clearance and urine NGAL (a marker of acute tubular necrosis), respectively. Since kidney failure in severe malaria is a consequence of severe ATN, severe kidney tubular damage was assessed qualitatively by RRT requirement.

\section{Methods \\ Study design and patients}

The study was an analysis of a subset of patients enrolled in two clinical trials assessing $\mathrm{N}$-acetylcysteine (2003-2005) and levamisole (2006-2010) as adjuvant therapy in severe falciparum malaria [21,22]. Of the 141 severe malaria patients enrolled in these two studies, all patients who had suPAR levels measured were included in this analysis $(\mathrm{N}=137$ out of 141). Both studies were conducted at Chittagong Medical College Hospital, Bangladesh, a 1,000-bed tertiary referral hospital with limited facilities for intensive care and RRT. Malaria transmission in this area is seasonal with peak transmission from June to August. This analysis builds on work presented from this cohort in 2011 [23]. Informed consent was obtained from each patient or designated family member. The Ministry of Health in Bangladesh, and Oxford Tropical Research Ethics Committee (OXTREC) granted ethical approval for both studies (registration numbers: ISRCTN20156397 and ISRCTN27232551).

Adults ( $\geq 16$ years) with slide-confirmed severe $P$. falciparum malaria were recruited. Criteria for severe malaria included: coma (Glasgow Coma Score <11), shock (systolic blood pressure (SBP) $<80 \mathrm{mmHg}$ with cool extremities), severe anaemia (haematocrit $<20 \%$ plus parasitaemia $>100,000 / \mu \mathrm{l}$ ), severe jaundice (total bilirubin $>3.0 \mathrm{mg} / \mathrm{dL}$ plus parasitaemia $>100,000 / \mu \mathrm{l}$ ), hyperparasitaemia (peripheral asexual stage parasitaemia $>10 \%$ ), acidosis (venous bicarbonate $<15 \mathrm{mmol} / \mathrm{L}$ ), hyperlactataemia (venous lactate $>4 \mathrm{mmol} / \mathrm{L}$ ), hypoglycaemia (blood glucose $<40 \mathrm{mg} / \mathrm{dL}$ ), convulsions ( $\geq$ two in 24 hours), pulmonary oedema, and/or renal failure (serum creatinine $>3 \mathrm{mg} / \mathrm{dL}$ ).

Patients were treated with parenteral artesunate (Guilin No 2 Pharmaceuticals, China) and managed according to WHO treatment guidelines [24]. Supportive treatment, including fluid resuscitation, was provided according to the treating physician's clinical judgment. RRT with haemodialysis or peritoneal dialysis was not available for all patients due to limited resources. Additional treatments have been previously described [21,22].

\section{Study procedures}

On enrolment, a complete medical history and examination were performed, and venous blood and urine collected. Admission venous sodium, potassium, chloride, glucose, blood urea nitrogen, haemoglobin, haematocrit, $\mathrm{pH}$ and bicarbonate were assessed using a portable, 
handheld analyzer (iSTAT, Abbott, Illinois, USA). Peripheral parasitaemia was assessed on admission and every six hours until parasite clearance, defined as two consecutive negative blood films. Plasma, serum and urine samples were processed and stored at $-80^{\circ} \mathrm{C}$ for further analysis in Bangkok, Thailand and Amsterdam, the Netherlands. The time and indication for RRT was recorded.

\section{Biomarker analysis}

Plasma suPAR concentrations were measured using suPARnostic $^{\text {tm }}$ ELISA (ViroGates, Copenhagen, Denmark), according to the manufacturer's instructions. Specimens were diluted to read within the calibration curve defined by quantitative standards. Reported results are the mean suPAR concentration $(\mathrm{ng} / \mathrm{ml})$ of duplicate wells for each specimen. Urine NGAL concentrations were measured using Human Lipocalin-2/NGAL ELISA (R\&D Systems, Abingdon, UK) according to the manufacturer's instructions. Multiple dilutions were tested in duplicate. The final urine NGAL concentration $(\mathrm{pg} / \mathrm{ml})$ was normalized to urinary creatinine and expressed as $\mathrm{pg} / \mathrm{mg}$ of creatinine (uNGAL/Ucr). Plasma PfHRP2 was assessed by commercial sandwich ELISA (Celisa, Cellabs, Sydney, Australia), according to the manufacturer's instructions with minor modifications [9]. Pooled reference plasma from 20 subjects with parasitaemia $>200,0000 / \mu$ l was calibrated to purified PfHRP2 standard curves (kindly provided by D Sullivan, John Hopkins School of Public Health, Baltimore, USA). Concentrations in duplicate plasma dilutions (1/25 to $1 / 3,125$ in PBS/0.01\%Tween) were determined according to the linear component of the standard curve. Cases where duplicates differed by more than $50 \%$ were re-assayed.

\section{Acute kidney injury}

AKI was defined by the estimated creatinine clearance, which is an accepted surrogate of kidney function measured by the glomerular filtration rate (GFR). Severity of AKI was classified as mild, moderate or severe dysfunction based on admission creatinine clearance $(\mathrm{CrCl})$ : mild $(\mathrm{CrCl}=60-89.9 \mathrm{ml} / \mathrm{min})$, moderate $(\mathrm{CrCl}=30$ $59.9 \mathrm{ml} / \mathrm{min})$ and severe $(\mathrm{CrCl}<30 \mathrm{ml} / \mathrm{min})$. No AKI was defined as $\mathrm{CrCl} \geq 90 \mathrm{ml} / \mathrm{min}$. $\mathrm{CrCl}$ was calculated using the Cockcroft-Gault formula [25]. No patient included in the analysis had a history of renal disease. Urine NGAL normalised to urine creatinine was used in this analysis as a biomarker for kidney damage, specifically acute tubular necrosis.

\section{Indication for renal replacement therapy}

Three clinicians (JH, PC and AMD) blinded to suPAR and PfHRP2 results, independently reviewed each patient file to determine whether patients met pre-defined criteria for RRT: hyperkalaemia ( $\mathrm{K}>5.5 \mathrm{mmol} / \mathrm{L}$ ), acidosis ( $\mathrm{pH}<7.35$, venous bicarbonate $<15 \mathrm{mmol} / \mathrm{L}$ ), fluid overload refractory to diuretics, uncontrolled seizures, pericarditis or rapid deterioration of renal function [23]. RRT was only deemed necessary in the setting of concomitant renal impairment (BUN $>30 \mathrm{mmol} / \mathrm{L}$ or creatinine $>200 \mu \mathrm{mol} / \mathrm{L}$ ), as adults with severe malaria may have the above complications in the absence of AKI [23].

\section{Statistical analysis}

Differences between AKI groups (mild, moderate, severe or no AKI) were compared by Student's $t$-test and MannWhitney- $U$ test for normally and non-normally distributed variables, respectively. Data were transformed to achieve a normal distribution where possible. A nonparametric test-for-trend, which is an extension of the Wilcoxon rank-sum test, was used to identify increasing or decreasing associations with AKI severity. Correlations between variables were assessed using Pearson's correlation coefficient. A robust regression model was constructed to assess the contributions of suPAR, PfHRP2, suPAR x PfHRP2 interaction, age and SBP to the variation in uNGAL/Ucr. Age and SBP were included in the model as they are well-established risk factors for kidney injury. There were no significant interactions between $\mathrm{CrCl}$ and suPAR, nor $\mathrm{CrCl}$ and $\mathrm{PfHRP2}$, therefore these terms were not included in the models. To assess the relationship of the same independent variables with the indication for RRT, a logistic model with stepwise exclusion of nonsignificant covariates was used. Improved model fit with the inclusion of the interaction term was confirmed using the likelihood ratio test. A $P$ value of less than 0.05 was considered significant. Statistical software used were STATA/IC 12.0 (STATA, TX, USA), and Prism 6 for Mac OS X (Graphpad Software, CA, USA).

\section{Results}

One-hundred and thirty-seven adults with severe falciparum malaria were included in this analysis (Figure 1).

\section{Baseline characteristics}

Baseline characteristics and patient outcomes are shown in Table 1. AKI was present in 106 patients (77\%), of whom $32(23 \%), 42(31 \%)$ and $32(23 \%)$ were classified as having mild, moderate and severe AKI, respectively. AKI classification using the WHO definition (creatinine $>3 \mathrm{mg} / \mathrm{dL}$ ) [24] rather than estimated $\mathrm{CrCl}$, failed to identify 11 (34\%) patients in the severe AKI group. These 11 patients had a geometric mean $\mathrm{CrCl}$ of $25 \mathrm{ml} /$ min, and 5/11 (45\%) required RRT. The WHO definition of AKI failed to identify 41/42 (98\%) patients with moderate AKI (geometric mean $\mathrm{CrCl} 42 \mathrm{ml} / \mathrm{min}$ ), of those 13/41 (32\%) required RRT. There was unanimous consensus among three independent physicians on 39 patients (28\%) 


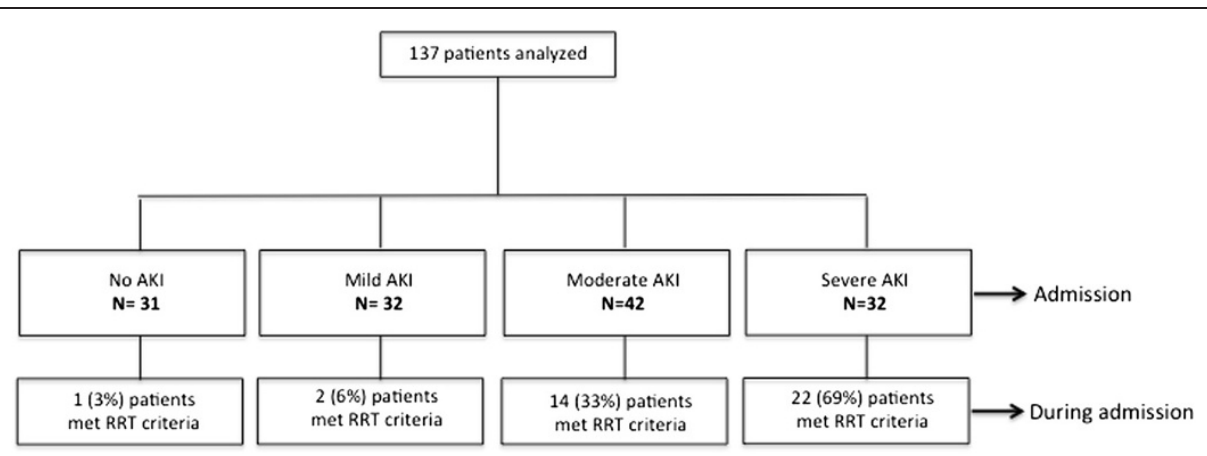

Figure 1 Consort diagram. After enrolment to the studies, patients admitted to Chittagong Medical College Hospital had blood and urine samples collected. Plasma and urine biomarkers were measured and correlated with the renal diagnosis and the subsequent hospital course. One patient with no AKI diagnosis on admission developed progressive renal impairment despite conservative measures and required RRT; this patient presented in deep coma with hyperlactataemia. AKI = acute kidney injury; RRT = renal replacement therapy.

who should have received RRT; 20 (51\%) did not receive RRT for logistical reasons. Two patients received haemodialysis and 17 patients received peritoneal dialysis within 48 hours of admission. The most frequent indication for RRT was acidosis (Table 2). Of the 19 patients who received RRT, eight (42\%) patients died; of the 20 patients who met criteria for RRT but could not receive it, 15 patients died (75\%). The overall case fatality rate was 53/137 (39\%); 50/53 (94\%) had cerebral malaria, 33/53 (62\%) had moderate or severe AKI, 35/53 (66\%) had hyperlactataemia, and 33/53 (62\%) had severe acidosis.

Increasing severity of AKI correlated with increasing age, and decreasing SBP and haematocrit (test-for-trend $p=0.003,0.048$ and 0.011 , respectively). Direct and indirect bilirubin increased and all measures of acid-base status (lactate, base deficit, bicarbonate, $\mathrm{pH}, \mathrm{pCO} 2$ ) worsened with increasing kidney injury severity (test-fortrend $p<0.001)$.

\section{Plasma soluble urokinase-type plasminogen activator receptor, Plasmodium falciparum histidine rich protein-2 and acute kidney injury}

Unlike peripheral parasitaemia, admission plasma PfHRP2 increased with worsening kidney function (test-for-trend $p<0.001$, Figure 2). Plasma PfHRP2 increased with both increasing creatinine $(r=0.49, P<0.001)$ and increasing uNGAL/Ucr $(r=0.29, P<0.002)$ (Figure 3A-B). Peripheral parasitaemia had a borderline correlation with serum creatinine $(r=0.17, P=0.05)$. Admission plasma suPAR increased with increasing AKI severity (test-for-trend $p<0.001$, Figure 2). There was a strong positive correlation between suPAR and both creatinine $(r=0.51, P<0.001)$ and uNGAL/Ucr $(r=0.38, P<0.001)$ (Figure 3C-D).

Plasma suPAR strongly correlated with PfHRP2 ( $r=$ $0.54, P<0.001)$; the interaction term (suPAR $\times$ PfHRP2) also increased with both increasing creatinine $(r=0.58$, $P<0.0001)$, increasing uNGAL/Ucr $(r=0.38, P<0.0001)$ and AKI severity (test-for-trend $p<0.0001$ ). This was further evaluated using linear regression with uNGAL/ Ucr as the dependent variable, representing acute tubular necrosis. In the univariate analysis suPAR, PfHRP2 and suPAR x PfHRP2 were significantly associated with a higher concentration of uNGAL/Ucr (Table 3). Multivariate analysis showed that only plasma suPAR and PfHRP2 were independently associated with higher uNGAL, predicting $18 \%$ of the variation in uNGAL/Ucr concentrations $\left(R^{2}=0.18\right.$; Table 3$)$.

Plasma suPAR and PfHRP2 concentrations were higher in patients requiring RRT $(P<0.001$, Figure 4$)$. Logistic regression was performed to further evaluate this relationship with RRT as the binary dependant variable, representing severe tubular damage in severe malaria. In univariate logistic analysis, increased suPAR, PfHRP2 and SUPAR x PfHRP2 were associated with increased odds for RRT requirement (Table 4). In a stepwise, multivariate, logistic regression model, increasing plasma suPAR, PfHRP2 and age increased the odds of RRT requirement $\left(R^{2}=\right.$ 0.27; Table 4).

\section{Relationship between plasma soluble urokinase-type plasminogen activator receptor, Plasmodium falciparum histidine rich protein-2 and mortality}

Plasma suPAR and PfHRP2 concentrations were not significantly higher in patients who died compared with those who survived: $29.03(25.38-33.22)$ versus 25.57 $(23.27-28.10) \mathrm{ng} / \mathrm{ml}$ for suPAR $(P=0.12)$ and 1,685 $(1,162-2,444)$ versus $1,629(1,185-2,237)$ for PfHRP2 $(P=0.89)$. Plasma suPAR and PfHRP2 were significantly elevated in patients who were acidotic (base deficit $>3.3 \mathrm{mmol} / \mathrm{L})$ compared to those who were not: 29.63 (27.07-32.44) versus 20.67 (18.02-23.71) $\mathrm{ng} / \mathrm{ml}$ for suPAR $(P<0.001)$ and $2,025(1,569-2,613)$ versus $816(469-$ $1,420)$ for PfHRP2 $(P=0.001)$. Standard base deficit was significantly elevated in patients who died compared to survivors; mean (SD), 11.8 (7.5) versus 6.5 (5.1) $(P<0.001)$. 
Table 1 Baseline characteristics by acute kidney injury severity and clinical outcome

\begin{tabular}{|c|c|c|c|c|c|c|}
\hline \multirow[t]{2}{*}{ Variable } & \multirow{2}{*}{$\frac{\text { Total }}{(n=137)}$} & \multirow{2}{*}{$\frac{\text { No AKI }}{(n=31)}$} & \multirow{2}{*}{$\frac{\text { Mild AKI }}{(n=32)}$} & \multirow{2}{*}{$\begin{array}{l}\text { Moderate AKI } \\
(n=42)\end{array}$} & \multirow{2}{*}{$\frac{\text { Severe AKI }}{(n=32)}$} & \multirow[t]{2}{*}{ Test-for-trenc } \\
\hline & & & & & & \\
\hline Age $\left(\right.$ years) ${ }^{a}$ & $35(23-45)$ & $26(18-35)$ & $33(25-40)$ & $35(21-50)$ & $40(28-48)$ & 0.003 \\
\hline Males $^{c}$ & $110(80)$ & $27(87)$ & $27(84)$ & $30(71)$ & $26(81)$ & 0.301 \\
\hline \multicolumn{7}{|l|}{ Clinical } \\
\hline $\mathrm{SBP}(\mathrm{mmHg})$ & $111(19)$ & $116(15)$ & $113(20)$ & $108(20)$ & $107(21)$ & 0.048 \\
\hline RR (breaths $/ \mathrm{min})^{\mathrm{b}}$ & $31(30-33)$ & $29(27-30)$ & $34(31-37)$ & $32(29-34)$ & $32(28-35)$ & 0.239 \\
\hline $\operatorname{GCS}(\# / 15)^{\mathrm{a}}$ & $8(6-11)$ & $8(7-10)$ & $8(5-10)$ & $9(6-11)$ & $9(5-12)$ & 0.937 \\
\hline \multicolumn{7}{|l|}{ Laboratory } \\
\hline $\mathrm{HCT}(\%)$ & $30(8)$ & $34(7)$ & $30(9)$ & $29(8)$ & $29(8)$ & 0.011 \\
\hline Parasitaemia & 73209 & 46723 & 33560 & 174140 & 78018 & 0.070 \\
\hline$(\# / \mu \mathrm{L})^{\mathrm{b}}$ & (50362-106419) & $(19688-110884)$ & (11984-93981) & $(120635-251377)$ & (36814-165340) & \\
\hline Creatinine & 1.53 & 0.69 & 1.11 & 1.75 & 3.80 & $<0.001$ \\
\hline$(\mathrm{mg} / \mathrm{dL})^{\mathrm{b}}$ & $(1.37-1.72)$ & $(0.63-0.76)$ & $(1.03-1.21)$ & $(1.60-1.91)$ & $(3.26-4.43)$ & \\
\hline BUN $(m g / d L)^{b}$ & $42(37-48)$ & $21(18-25)$ & $27(23-32)$ & $57(50-65)$ & $88(73-105)$ & $<0.001$ \\
\hline $\mathrm{CrCl}$ & 50.6 & 123.3 & 72.5 & 41.7 & 19.3 & $<0.001$ \\
\hline$(\mathrm{ml} / \mathrm{min})^{\mathrm{b}}$ & $(44.9-57.0)$ & (112.8-134.8) & $(69.8-75.3)$ & $(39.0-44.5)$ & $(17.0-21.8)$ & \\
\hline Potassium (mmol/L) & $4.4(1.0)$ & $4.0(0.7)$ & $4.4(1.1)$ & $4.4(0.7)$ & $4.6(1.4)$ & 0.031 \\
\hline Sodium (mmol/L) & $133(7)$ & $129(7)$ & $134(5)$ & $133(8)$ & $133(6)$ & 0.069 \\
\hline Albumin $(g / L)$ & $29(5)$ & $31(5)$ & $30(4)$ & $28(5)$ & $27(6)$ & $<0.001$ \\
\hline Total bilirubin $(\mathrm{mg} / \mathrm{dL})^{\mathrm{b}}$ & $4.5(3.8-5.4)$ & $4.1(2.8-5.9)$ & $3.1(2.3-4.1)$ & $4.9(3.5-6.7)$ & $6.7(4.7-9.6)$ & 0.011 \\
\hline Direct bilirubin $(\mathrm{mg} / \mathrm{dL})^{b}$ & $1.8(1.5-2.2)$ & $1.2(0.8-2.0)$ & $1.1(0.8-1.5)$ & $2.2(1.5-3.2)$ & $3.4(2.2-5.2)$ & $<0.001$ \\
\hline $\operatorname{ALT}(U / L)^{b}$ & $30(25-36)$ & $22(17-28)$ & $30(21-43)$ & $36(25-51)$ & $34(23-51)$ & 0.064 \\
\hline Base excess (mmol/L) & $-9(7)$ & $-4(4)$ & $-5(4)$ & $-11(7)$ & $-13(7)$ & $<0.001$ \\
\hline Bicarbonate $(\mathrm{mmol} / \mathrm{L})$ & $17(5)$ & $21(4)$ & $19(4)$ & $14(5)$ & $14(4)$ & $<0.001$ \\
\hline $\mathrm{pH}$ & $7.37(0.13)$ & $7.42(0.08)$ & $7.42(0.09)$ & $7.35(0.12)$ & $7.30(0.17)$ & $<0.001$ \\
\hline pCO2 (mmHg) & $28(7)$ & $32(6)$ & $29(7)$ & $25(8)$ & $26(7)$ & $<0.001$ \\
\hline Lactate $(\mathrm{mmol} / \mathrm{L})^{\mathrm{b}}$ & $5.1(4.6-5.6)$ & $4.3(3.7-5.1)$ & $3.9(3.2-4.7)$ & $7.1(6.0-8.3)$ & $4.9(3.8-6.4)$ & 0.029 \\
\hline \multicolumn{7}{|l|}{ Biomarkers } \\
\hline HRP2 & 1649 & 678 & 1413 & 2419 & 2833 & $<0.001$ \\
\hline$(\mathrm{ng} / \mathrm{ml})^{\mathrm{b}}$ & $(1297-2096)$ & (397-1156) & $(967-2064)$ & $(1715-3413)$ & (1648-4872) & \\
\hline uNGAL/Ucr & 1262 & 750 & 1,012 & 1281 & 2549 & $<0.001$ \\
\hline$(\mathrm{pg} / \mathrm{mg} \mathrm{cr})^{\mathrm{b}}$ & $(1097-1451)$ & (589-956) & $(745-1376)$ & $(1066-1541)$ & (1943-3345) & \\
\hline \multicolumn{7}{|l|}{ Outcomes } \\
\hline RRT indicated ${ }^{c}$ & $39(28)$ & $1(3)$ & $2(6)$ & $14(33)$ & $22(69)$ & $<0.001$ \\
\hline Death $^{c}$ & $53(39)$ & $12(39)$ & $8(25)$ & $19(45)$ & $14(44)$ & 0.333 \\
\hline
\end{tabular}

All values are mean (SD) unless otherwise specified; ${ }^{a}$ median (IQR), ${ }^{\text {}}$ geometric mean $(95 \% \mathrm{Cl}),{ }^{\mathrm{c}}$ number $(\%) . P<0.05$ using test-for-trend; significant in bold. $\mathrm{AKI}=$ acute kidney injury; $\mathrm{SBP}=$ systolic blood pressure; $\mathrm{RR}=$ respiratory rate; $\mathrm{GCS}=$ Glasgow Coma Scale; $\mathrm{HCT}=$ haematocrit; $\mathrm{BUN}=$ blood urea nitrogen; $\mathrm{CrCl}=$ creatinine clearance; $\mathrm{ALT}=$ alanine transaminase; $\mathrm{pCO} 2$ = venous partial pressure carbon dioxide; $\mathrm{HRP} 2=$ Plasmodium falciparum histidine rich protein 2; suPAR = soluble urokinase-type plasminogen activator receptor; uNGAL/Ucr = urine neutrophil gelatinase-associated lipocalin corrected for urine creatinine; RRT = renal replacement therapy.

\section{Discussion}

In this study of adult patients with severe falciparum malaria, admission plasma suPAR and PfHRP2 were strongly and independently associated with AKI, and a later requirement for RRT. As suPAR is an indirect measure of mononuclear cell activation, and PfHRP2 a measure of sequestered parasite biomass, these results suggest that both mechanisms contribute to the pathogenesis of AKI. These findings are concordant with postmortem renal histopathological findings in patients with 
Table 2 Indication for renal replacement therapy

\begin{tabular}{ll}
\hline Indication & Number \\
\hline Renal impairment and acidosis & 20 \\
Renal impairment and hyperkalaemia & 0 \\
Renal impairment, acidosis and hyperkalaemia & 6 \\
Renal impairment, acidosis and convulsions & 2 \\
Renal impairment, acidosis, hyperkalaemia and convulsions & 3 \\
Worsening renal function despite conservative measures & 5 \\
Worsening renal function and convulsions & 1 \\
Renal impairment and pulmonary oedema & 1 \\
Renal impairment, acidosis and pulmonary oedema & 1 \\
Total & $\mathbf{3 9}$ \\
\hline
\end{tabular}

falciparum malaria that shows both PRBC sequestration and mononuclear cell infiltration in glomerular and peritubular capillaries [6].

Multivariate regression analysis showed that plasma PfHRP2 independently correlated with uNGAL, and a requirement for RRT. Histopathology of falciparum malaria-associated AKI shows a significant increase in sequestration among patients with a creatinine $>3 \mathrm{mg} /$ $\mathrm{dL}$, which defines AKI according to WHO malaria treatment guidelines [6]. Overall, disease severity and the severity of metabolic acidosis have also been shown to correlate strongly with plasma PfHRP2 concentrations [9-12,26]. PfHRP2 was significantly elevated in patients who were acidotic. Peripheral parasitaemia does not reflect the pathogenic-sequestered parasite burden that causes impaired microvascular flow, and the correlation between parasitaemia and total parasite burden is variable. This might explain why the presented results contrast with other studies, in that an association between hyperparasitaemia and AKI severity was not found $[6,27,28]$. However, plasma PfHRP2, representing the total parasite biomass including the sequestered parasites, strongly correlated with AKI defined by either $\mathrm{WHO}$ or $\mathrm{CrCl}$ classification. The correlation between PfHRP2 and creatinine was also stronger than the correlation between peripheral parasitaemia and creatinine. Sequestered PRBCs occluding the renal microcirculation may explain why increasing the overall renal blood flow in severe malaria does not result in a change in renal oxygen consumption [29]; as only patent vessels free of sequestered PRBCs would continue to be perfused and PRBC occluded vessels would not be recruited.

Plasma suPAR increased with deteriorating renal function defined by $\mathrm{CrCl}$ classification and WHO criteria, urine NGAL and independently predicted RRT requirement. Plasma suPAR is positively correlated with creatinine in patients with Hantavirus and critically ill patients, and inversely correlated with estimated glomerular filtration rate (GFR) in chronic kidney disease

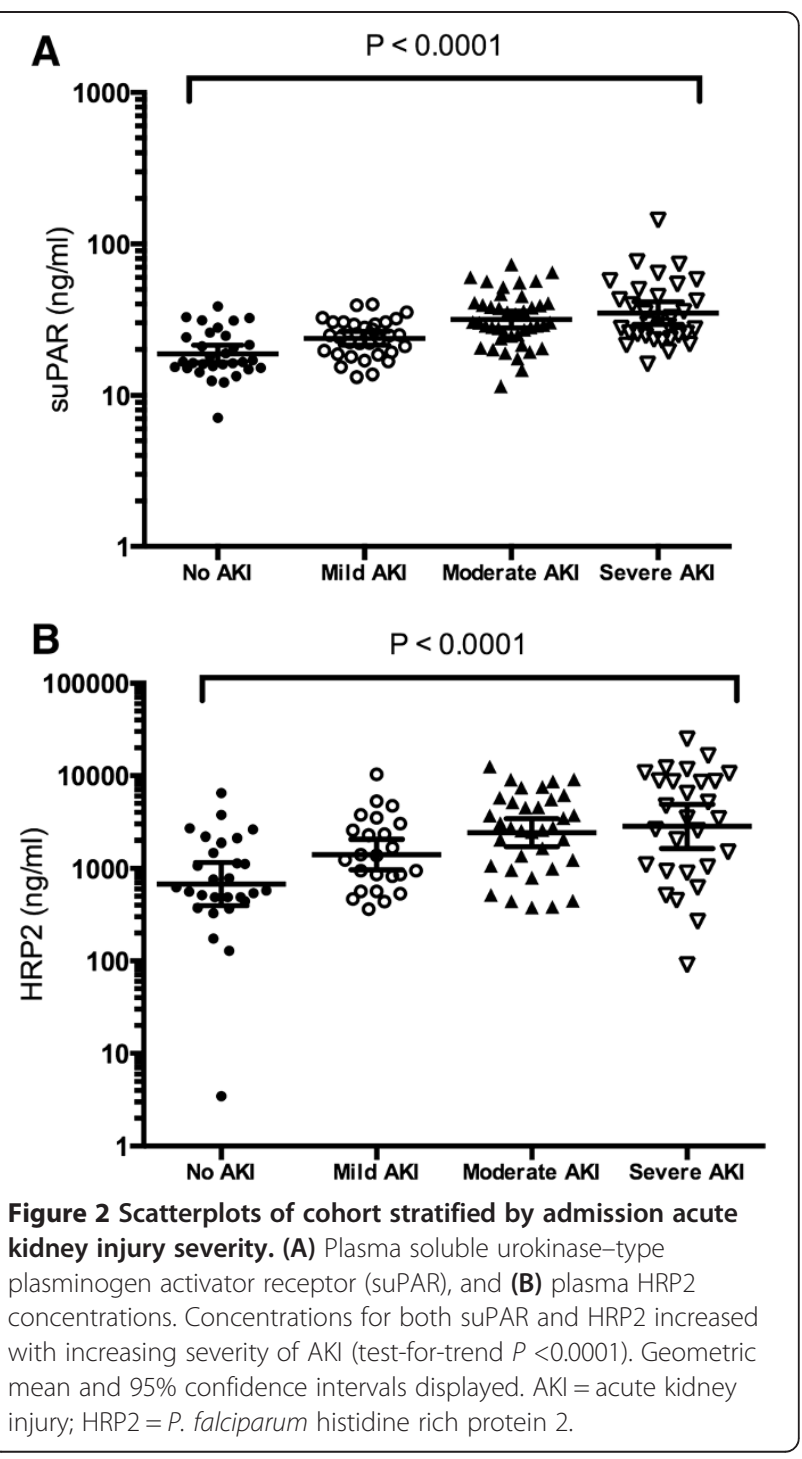

[30-33]. Histology of brain tissue from cerebral malaria patients shows an increase in uPAR expression in macrophage and endothelial cells spatially limited to areas with PRBCs sequestered in the microvasculature [34]. This is the first time elevated suPAR has been shown to be associated with kidney injury and dysfunction in malaria. This supports that the histopathological mononuclear cell accumulation in glomerular and peritubular capillaries contribute to the acute tubular necrosis in patients with a creatinine above and below $3 \mathrm{mg} /$ $\mathrm{dL}$, despite a difference in observed sequestration of PRBCs. It is possible that sequestration acts as an endothelial nidus and subsequent positive feedback loop for increased suPAR-mediated mononuclear cell recruitment and immune activation resulting in more severe tubular damage. Cell-to-cell contact between endothelial cells and monocytes increases suPAR release [14] and suPAR subsequently recruits more monocytes via its 

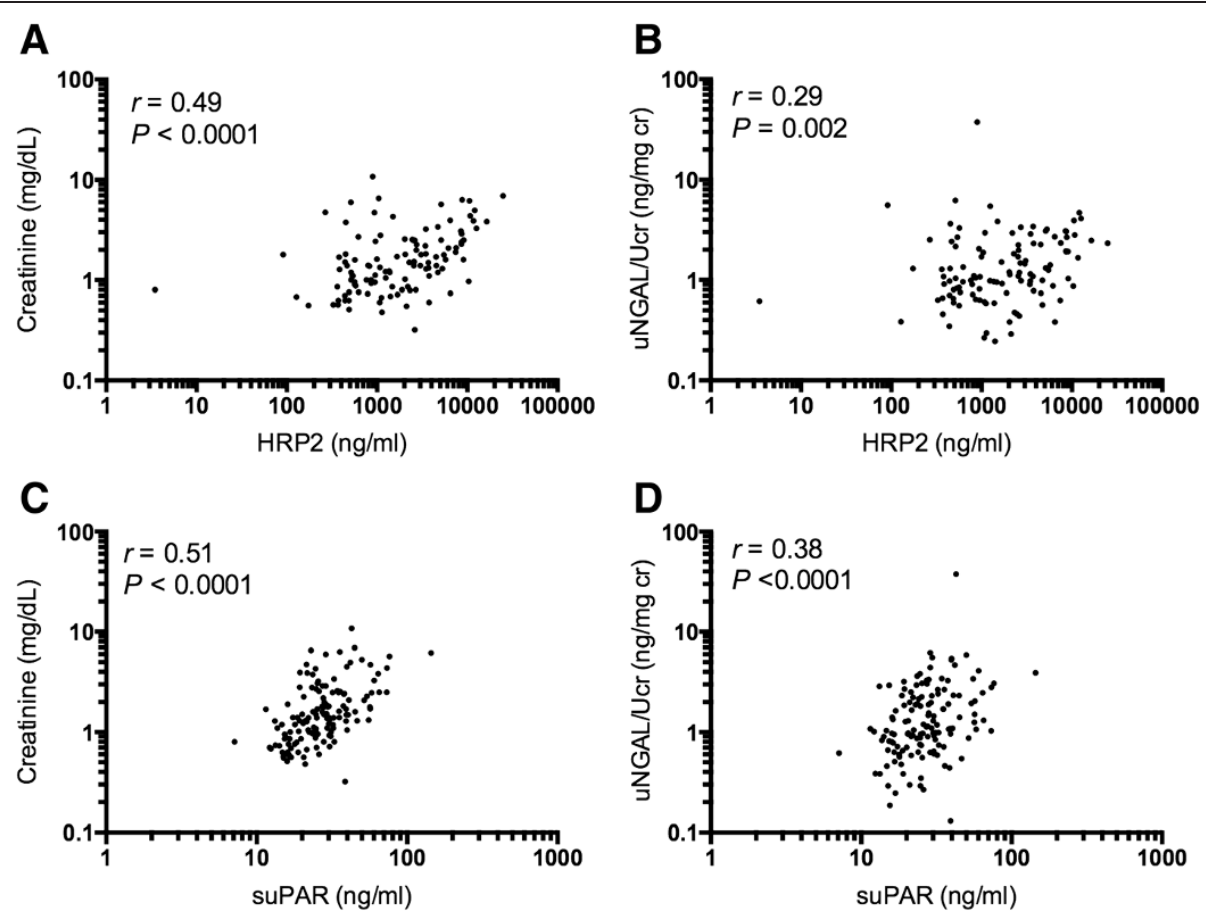

Figure 3 Correlations of variables involved in acute kidney injury. Correlations of variables proposed to be involved in the pathogenesis of acute tubular necrosis in malaria associated AKI with marker of renal dysfunction (creatinine) and marker of kidney damage (UNGAL/Ucr). Pearson's correlation coefficient between plasma P. falciparum histidine rich protein 2 (HRP2) and (A) serum creatinine; and (B) uNGAL/Ucr. Pearson's correlation coefficient between suPAR and (C) serum creatinine; and (D) UNGAL/Ucr. All variables were log transformed $\left(\log _{10}\right)$ for correlation plots and Pearson's analysis. suPAR = soluble urokinase-type plasminogen activator receptor; uNGAL/Ucr = urine neutrophil gelatinase-associated lipocalin corrected for urine creatinine.

chemo-attractant effector function [35,36]. Upon schizont rupture, haemozoin (malaria pigment) acts as antigen to activate monocytes resulting in release of proinflammatory cytokines and chemokines [37,38]. This could initiate a positive feedback loop since TNF- $\alpha$ increases expression of UPAR on monocytes resulting in accelerated cleavage of suPAR and consequent monocyte recruitment $[35,38]$. Indeed, mononuclear cells loaded with pigment are observed in glomerular and peritubular microvessels on histopathology [6]. As elevated suPAR concentrations have not been shown to be directly pro- inflammatory [39], the accumulation of activated monocytes releasing cytokines are the likely effectors contributing to renal tubular cell damage in severe malaria.

In this study there was no association between suPAR and mortality, which contrasts with a study of African children with malaria where increased suPAR concentrations were associated with poor clinical outcomes [16]. This may be because there was a low mortality rate (2\%) in the African study, suggesting less severe disease. The entire cohort presented here was severely ill with a high mortality rate and higher suPAR concentrations compared

Table 3 Linear regression analysis of variables contributing to urine NGAL/Ucr variability in patients with severe malaria

\begin{tabular}{|c|c|c|c|c|}
\hline \multirow[b]{2}{*}{ Variable } & \multicolumn{2}{|l|}{ Univariate analysis } & \multicolumn{2}{|c|}{ Multivariate model $\left(R^{2}=0.18\right)$} \\
\hline & $\beta(95 \% \mathrm{Cl})^{\mathrm{a}}$ & $P$ & $\beta(95 \% \mathrm{Cl})^{\mathrm{a}}$ & $P$ \\
\hline SUPAR & $21.57(12.20-30.95)$ & $<0.001$ & $16.54(6.36-26.71)$ & 0.002 \\
\hline PfHRP2 & $0.11(0.06-0.15)$ & $<0.001$ & $0.07(0.02-0.11)$ & 0.003 \\
\hline SUPAR $\times$ PfHRP2 & $0.002(0.001-0.003)$ & $<0.001$ & - & - \\
\hline SBP & $0.16(-8.62-8.94)$ & 0.971 & - & - \\
\hline Age & $-12.02(-25.32-1.28)$ & 0.076 & - & - \\
\hline
\end{tabular}

${ }^{\mathrm{a}}$ Regression coefficient $(\beta)$ with $95 \%$ confidence intervals (Cls) showing the estimated increase in the urine concentration of NGAL (pg/ml) corrected for urine creatinine (uNGAL/Ucr pg/mg of creatinine) predicted by 1 unit increases in the independent (predictor) variables using robust regression analysis. Significant in bold. 


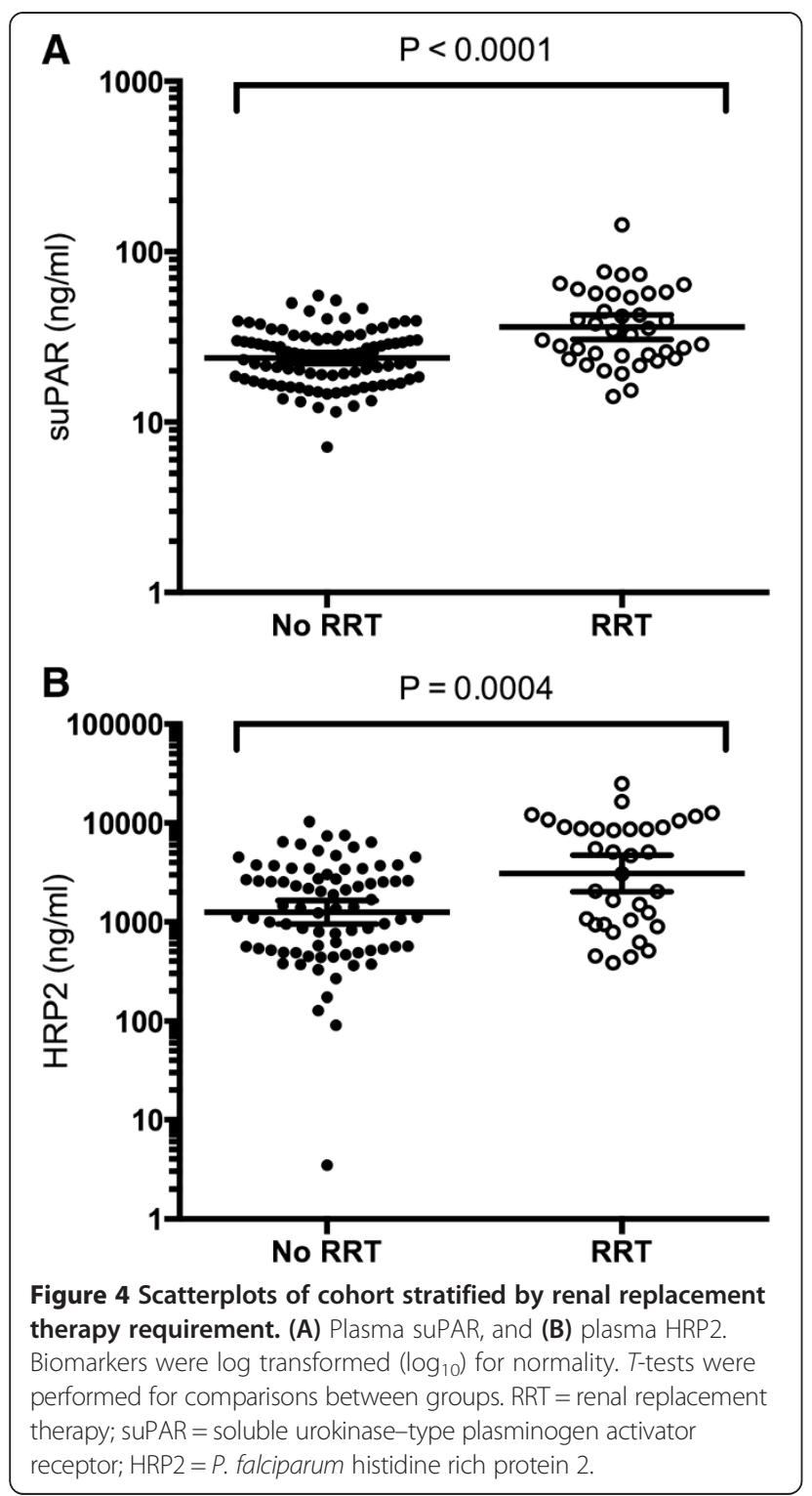

Figure 4 Scatterplots of cohort stratified by renal replacement therapy requirement. (A) Plasma SUPAR, and (B) plasma HRP2. Biomarkers were log transformed $\left(\log _{10}\right)$ for normality. T-tests were therapy; suPAR = soluble urokinase-type plasminogen activator receptor; $\mathrm{HRP2}=P$. falciparum histidine rich protein 2 . to the African study [16]; including uncomplicated malaria patients in this analysis may have shown an association between suPAR concentration and mortality.

There are limitations to this study. Both suPAR and HRP2 measured in the plasma are not organ specific markers of monocyte activation and sequestration, respectively. However, kidney specific markers of these phenomena currently do not exist. The justification of the analyses of plasma suPAR and HRP2 is based on the histopathology that has shown sequestration of PRBCs and mononuclear cell infiltration in the kidney. Since suPAR was measured in plasma, the concentrations measured likely represent production by activated host immune cells, in particular mononuclear cells, however endothelial sources could also contribute. As suPAR has renal clearance, elevated plasma levels can be a consequence of reduced GFR [31,33]. However, in the multiple regression models, interaction terms of $\mathrm{CrCl}$, suPAR and PfHRP2 did not reveal a significant contribution, and the association between suPAR and indication for RRT was also found in patients presenting without AKI on admission. It has been shown that plasma HRP2 half life is not correlated with biochemical evidence of kidney dysfunction [9]. Urine NGAL as a biomarker for renal tubular damage has limitations, as its excretion depends on the timing in relation to the initial renal injury [40]. However, NGAL is an 'induced' biomarker, thus excretion is continued with ongoing renal stress [40]. Using renal biopsy as a reference standard for ATN was not feasible or ethically indicated in this study, so RRT requirement was used as an alternative endpoint. Finally, the sample size in this study was relatively small and patient data were reviewed retrospectively. However, this assessment was done according to pre-defined criteria and three independent specialist physicians were in full agreement.

\section{Conclusions}

This study suggests that parasite sequestration and immune activation contribute to the pathogenesis of AKI in severe falciparum malaria. Early diagnosis of falciparum

Table 4 Logistic regression analysis of variables predicting renal replacement therapy in patients with severe malaria

\begin{tabular}{|c|c|c|c|c|}
\hline \multirow[b]{2}{*}{ Variable } & \multicolumn{2}{|c|}{ Univariate analysis } & \multicolumn{2}{|c|}{ Multivariate model $\left(R^{2}=0.27\right)$} \\
\hline & OR $(95 \% \mathrm{Cl})^{\mathrm{b}}$ & $P$ & OR $(95 \% \mathrm{Cl})^{\mathrm{b}}$ & $P$ \\
\hline SUPAR & $1.07(1.04-1.11)$ & $<0.001$ & $1.07(1.03-1.12)$ & 0.002 \\
\hline $\mathrm{PAHRP} 2^{1 / 2}$ & $1.03(1.02-1.05)$ & $<0.001$ & $1.02(1.00-1.04)$ & 0.026 \\
\hline $\operatorname{suPAR} R^{1 / 2} \times P A H R P 2^{1 / 2}$ & $1.01(1.00-1.01)$ & $<0.001$ & - & - \\
\hline SBP & $1.01(0.99-1.03)$ & 0.522 & - & - \\
\hline Age & $1.02(0.99-1.05)$ & 0.123 & $1.05(1.01-1.10)$ & 0.010 \\
\hline
\end{tabular}

${ }^{\mathrm{b}}$ Odds ratios (OR) with $95 \% \mathrm{Cls}$ were determined for renal replacement therapy (RRT) associated with 1-U changes in the independent variables. Significant variables are shown in bold. PfHRP2 was square root transformed to normalize skewed data. Significant in bold.

$\mathrm{OR}=$ odds ratio; $\mathrm{Cl}=$ confidence intervals; $\mathrm{UNGAL} / \mathrm{Ucr}=$ urine neutrophil-associated gelatinase lipocalin corrected for urine creatinine; suPAR = soluble urokinase plasminogen activator receptor; $P f H R P 2=P$. falciparum histidine rich protein $2 ; \mathrm{SBP}=$ systolic blood pressure. 
malaria and treatment with artemisinin-based antimalarials will rapidly eliminate ring-staged parasites, preventing their microvascular sequestration in vital organs, including the kidney. Deeper understanding of the immunopathological mechanisms underlying AKI in severe malaria might reveal novel, targeted, treatment options to further prevent this common and life-threatening complication.

\begin{abstract}
Abbreviations
suPAR: Plasma soluble urokinase-type plasminogen activator receptor: PfHRP2: Plasma Plasmodium falciparum histidine rich protein 2; AKI: Acute kidney injury; RRT: Renal replacement therapy; UNGAL: Urine neutrophil gelatinase-associated lipocalin; Ucr: Urine creatinine; UNGAL/Ucr: Urine neutrophil gelatinase-associated lipocalin corrected for urine creatinine; $\mathrm{CrCl}$ : Creatinine clearance; ATN: Acute tubular necrosis; SBP: Systolic blood pressure; PRBCs: Parasitized red blood cells; GFR: Glomerular filtration rate; WHO: World Health Organization.
\end{abstract}

\section{Competing interests}

MJS is an advisor of Virogates A/S, Denmark. He has no financial interests in the company. All other authors declare that they have no competing interests.

\section{Authors' contributions}

KP contributed to managing patients, sample collection, statistical analysis and manuscript preparation. AAR contributed to data analysis and manuscript preparation. JH contributed to patient management, sample collection and manuscript revision. MUH, SA and AG supervised the study and clinical care of the patients. RJM and PC contributed to patient management, data collection and entry and manuscript revision. PMS provided the suPAR measurements. SJ assisted with statistical analysis. GDHT assisted with data interpretation and critical manuscript revision. AMD and MSJ were the senior supervisors, conceived of and designed the study, assisted with statistical analysis and manuscript revision. All authors read and approved the final manuscript.

\section{Acknowledgements}

We thank the patients, staff and directors at Chittagong Medical College Hospital, for making this study possible; the laboratory scientists and research physicians for their dedication in data collection; Md Safiqul Mostafa Choudury, Sanjib Kanti Paul, and Sumon Sarma for their instrumental assistance in Bangladesh. Mahidol-Oxford Tropical Medicine Research Unit is funded by the Wellcome Trust of Great Britain.

\section{Author details}

${ }^{1}$ Mahidol Oxford Tropical Medicine Research Unit, Faculty of Tropical Medicine, Mahidol University, Bangkok, Thailand. ${ }^{2}$ Department of Anesthesiology, Zaans Medical Hospitals, Zaandam, the Netherlands. ${ }^{3}$ Department of Intensive Care Medicine \& Laboratory for Experimental Intensive Care and Anesthesiology (L E I C A), Academic Medical Center, University of Amsterdam, Amsterdam, the Netherlands. ${ }^{4}$ Menzies School of Health Research, Darwin, Australia. ${ }^{5}$ Chittagong Medical College Hospital, Chittagong, Bangladesh. ${ }^{6}$ Centre for Tropical Medicine, Nuffield Department of Medicine, University of Oxford, Oxford, UK.

Received: 15 January 2014 Accepted: 26 February 2014 Published: 12 March 2014

\section{References}

1. Dondorp A, Nosten F, Stepniewska K, Day NP, White NJ, South East Asian Quinine Artesunate Malaria Trial (SEAQUAMAT) group: Artesunate versus quinine for treatment of severe falciparum malaria: a randomised trial. Lancet 2005, 366:717-725.

2. Trang TT, Phu NH, Vinh H, Hien TT, Cuong BM, Chau TT, Mai NT, Waller DJ, White NJ: Acute renal failure in patients with severe falciparum malaria. Clin Infect Dis 1992, 15:874-880.

3. von Seidlein L, Olaosebikan R, Hendriksen IC, Lee SJ, Adedoyin OT, Agbenyega T, Nguah SB, Bojang K, Deen JL, Evans J, Fanello Cl, Gomes E, Pedro AJ, Kahabuka C, Karema C, Kivaya E, Maitland K, Mokuolu OA, Mtove
G, Mwanga-Amumpaire J, Nadjm B, Nansumba M, Ngum WP, Onyamboko MA, REyburn H, Salkulthaew T, Silamut K, Tshefu AK, Umulisa N, Gesase S, Day NP, White NJ, Dondorp AM: Predicting the clinical outcome of severe falciparum malaria in african children: findings from a large randomized trial. Clin Infect Dis 2012, 54:1080-1090.

4. White NJ, Pukrittayakamee S, Hien TT, Faiz MA, Mokuolu OA, Dondorp AM: Malaria. Lancet 2013, 383:723-735.

5. Mukherjee AP, White JC, Lau KS: Falciparum malaria associated with jaundice, renal failure and anaemia. Trans R Soc Trop Med Hyg 1971, 65:808-814.

6. Nguansangiam S, Day NP, Hien TT, Mai NT, Chaisri U, Riganti M, Dondorp AM, Lee SJ, Phu NH, Turner GD, White NJ, Ferguson DJ, Pongponratn E: A quantitative ultrastructural study of renal pathology in fatal Plasmodium falciparum malaria. Trop Med Int Health 2007, 12:1037-1050.

7. Sitprija V, Indraprasit S, Pochanugool C, Benyajati C, Piyaratn P: Renal failure in malaria. Lancet 1967, 1:185-188.

8. Desakorn V, Dondorp AM, Silamut K, Pongtavornpinyo W, Sahassananda D, Chotivanich K, Pitisuttithum P, Smithyman AM, Day NP, White NJ: Stagedependent production and release of histidine-rich protein 2 by Plasmodium falciparum. Trans R Soc Trop Med Hyg 2005, 99:517-524.

9. Dondorp AM, Desakorn V, Pongtavornpinyo W, Sahassananda D, Silamut K Chotivanich K, Newton PN, Pitisuttithum P, Smithyman AM, White NJ, Day NP: Estimation of the total parasite biomass in acute falciparum malaria from plasma PfHRP2. PLoS Med 2005, 2:e204.

10. Hendriksen IC, Mwanga-Amumpaire J, von Seidlein L, Mtove G, White $L$, Olaosebikan R, Lee SJ, Tshefu AK, Woodrow C, Amos B, Karema C, Saiwaew S, Maitland K, Gomes E, Pan-Ngum W, Gesase S, Silamut K, Reyburn H, Joseph S, Chotivanich K, Fanello Cl, Day NP, White NJ, Dondorp AM: Diagnosing severe falciparum malaria in parasitaemic African children: a prospective evaluation of plasma PfHRP2 measurement. PLOS Med 2012, 9:e1001297.

11. Rubach MP, Mukemba J, Florence S, John B, Crookston B, Lopansri BK, Yeo TW, Piera KA, Alder SC, Weinberg JB, Anstey NM, Granger DL, Mwaikambo ED: Plasma Plasmodium falciparum histidine-rich protein-2 concentrations are associated with malaria severity and mortality in Tanzanian children. PloS One 2012, 7:e35985.

12. Yeo TW, Lampah DA, Gitawati R, Tjitra E, Kenangalem E, Piera K, Price RN, Duffull SB, Celermajer DS, Anstey NM: Angiopoietin-2 is associated with decreased endothelial nitric oxide and poor clinical outcome in severe falciparum malaria. Proc Natl Acad Sci USA 2008, 105:17097-17102.

13. Maas RJ, Deegens JK, Wetzels JF: Serum suPAR in patients with FSGS: trash or treasure? Pediatr Nephrol 2013, 28:1041-1048.

14. Mustjoki S, Sidenius N, Vaheri A: Enhanced release of soluble urokinase receptor by endothelial cells in contact with peripheral blood cells. FEBS Lett 2000, 486:237-242.

15. Wagner SN, Atkinson MJ, Wagner C, Hofler H, Schmitt M, Wilhelm O: Sites of urokinase-type plasminogen activator expression and distribution of its receptor in the normal human kidney. Histochem Cell Biol 1996, 105:53-60.

16. Ostrowski SR, Ullum H, Goka BQ, Hoyer-Hansen G, Obeng-Adjei G, Pedersen BK, Akanmori BD, Kurtzhals JA: Plasma concentrations of soluble urokinase-type plasminogen activator receptor are increased in patients with malaria and are associated with a poor clinical or a fatal outcome. $J$ Infect Dis 2005, 191:1331-1341.

17. Perch M, Kofoed P, Fischer TK, Co F, Rombo L, Aaby P, Eugen-Olsen J: Serum levels of soluble urokinase plasminogen activator receptor is associated with parasitemia in children with acute Plasmodium falciparum malaria infection. Parasite Immunol 2004, 26:207-211.

18. Haase M, Devarajan P, Haase-Fielitz A, Bellomo R, Cruz DN, Wagener G, Krawczeski CD, Koyner JL, Murray P, Zappitelli M, Goldstein SL, Makris K, Ronco C, Martensson J, Martling CR, Venge P, Siew E, Ware LB, Ikizler TA, Mertens PR: The outcome of neutrophil gelatinase-associated lipocalinpositive subclinical acute kidney injury: a multicenter pooled analysis of prospective studies. J Am Coll Cardiol 2011, 57:1752-1761.

19. Mishra J, Ma Q, Prada A, Mitsnefes M, Zahedi K, Yang J, Barasch J, Devarajan $P$ : Identification of neutrophil gelatinase-associated lipocalin as a novel early urinary biomarker for ischemic renal injury. J Am Soc Nephrol 2003, 14:2534-2543.

20. Singer E, Marko L, Paragas N, Barasch J, Dragun D, Muller DN, Budde K, Schmidt-Ott KM: Neutrophil gelatinase-associated lipocalin: pathophysiology and clinical applications. Acta Physiol (Oxf) 2013, 207:663-672.

21. Charunwatthana P, Abul Faiz M, Ruangveerayut R, Maude RJ, Rahman MR, Roberts $\sqcup$, 2nd, Moore K, Bin Yunus E, Hoque MG, Hasan MU, Lee SJ, 
Pukrittayakamee S, Newton PN, White NJ, Day NP, Dondorp AM:

$\mathrm{N}$-acetylcysteine as adjunctive treatment in severe malaria: a randomized, double-blinded placebo-controlled clinical trial. Crit Care Med 2009, 37:516-522.

22. Maude RJ, Silamut K, Plewes K, Charunwatthana P, Ho M, Abul Faiz M, Rahman R, Hossain MA, Hassan MU, Bin Yunus E, Hoque G, Islam F, Ghose A, Hanson J, Schlatter J, Lacey R, Eastaugh A, Tarning J, Lee SJ, White NJ, Chotivanich K, Day NP, Dondorp AM: Randomized controlled trial of levamisole hydrochloride as adjunctive therapy in severe falciparum malaria with high parasitemia. J Infect Dis 2014, 209:120-129.

23. Hanson J, Hasan MM, Royakkers AA, Alam S, Charunwatthana P, Maude RJ, Douthwaite ST, Yunus EB, Mantha ML, Schultz MJ, Faiz MA, White NJ, Day NP, Dondorp AM: Laboratory prediction of the requirement for renal replacement in acute falciparum malaria. Malar J 2011, 10:217.

24. WHO: Guidelines for the Treatment of Malaria. Geneva: World Health Organization; 2010 [http://www.who.int/malaria/publications/atoz/9789241547925/en/]

25. Cockcroft DW, Gault MH: Prediction of creatinine clearance from serum creatinine. Nephron 1976, 16:31-41.

26. Day NP, Phu NH, Mai NT, Chau TT, Loc PP, Chuong LV, Sinh DX, Holloway P, Hien TT, White NJ: The pathophysiologic and prognostic significance of acidosis in severe adult malaria. Crit Care Med 2000, 28:1833-1840.

27. Prakash J, Singh AK, Gujrati S, Maheshwari A: Acute renal failure in malaria: changing trends. Indian I Nephrol 2002, 12:113-117.

28. Segasothy M, Swaminathan M, Kong NC: Acute renal failure in falciparum malaria. Med J Malaysia 1994, 49:412-415.

29. Day NP, Phu NH, Mai NT, Bethell DB, Chau TT, Loc PP, Chuong LV, Sinh DX, Solomon T, Haywood G, Hien TT, White NJ: Effects of dopamine and epinephrine infusions on renal hemodynamics in severe malaria and severe sepsis. Crit Care Med 2000, 28:1353-1362.

30. Koch A, Voigt S, Kruschinski C, Sanson E, Duckers H, Horn A, Yagmur E, Zimmermann H, Trautwein C, Tacke F: Circulating soluble urokinase plasminogen activator receptor is stably elevated during the first week of treatment in the intensive care unit and predicts mortality in critically ill patients. Crit Care 2011, 15:R63.

31. Maas RJ, Wetzels JF, Deegens JK: Serum-soluble urokinase receptor concentration in primary FSGS. Kidney Int/ 2012, 81:1043-1044.

32. Outinen TK, Tervo L, Makela S, Huttunen R, Maenpaa N, Huhtala H, Vaheri A, Mustonen J, Aittoniemi J: Plasma levels of soluble urokinase-type plasminogen activator receptor associate with the clinical severity of acute Puumala hantavirus infection. PLoS One 2013, 8:e71335.

33. Pawlak K, Ulazka B, Mysliwiec M, Pawlak D: Vascular endothelial growth factor and UPA/suPAR system in early and advanced chronic kidney disease patients: a new link between angiogenesis and hyperfibrinolysis? Trans/ Res 2012, 160:346-354.

34. Fauser $\mathrm{S}$, Deininger MH, Kremsner PG, Magdolen V, Luther T, Meyermann R, Schluesener $\mathrm{HJ}$ : Lesion associated expression of urokinase-type plasminogen activator receptor (UPAR, CD87) in human cerebral malaria. J Neuroimmunol 2000, 111:234-240.

35. Pliyev BK: Activated human neutrophils rapidly release the chemotactically active D2D3 form of the urokinase-type plasminogen activator receptor (UPAR/CD87). Mol Cell Biochem 2009, 321:111-122.

36. Resnati M, Guttinger M, Valcamonica S, Sidenius N, Blasi F, Fazioli F: Proteolytic cleavage of the urokinase receptor substitutes for the agonist-induced chemotactic effect. EMBO J 1996, 15:1572-1582.

37. Kwiatkowski D, Cannon JG, Manogue KR, Cerami A, Dinarello CA, Greenwood BM: Tumour necrosis factor production in falciparum malaria and its association with schizont rupture. Clin Exp Immunol 1989, 77:361-366.

38. Polimeni M, Valente E, Aldieri E, Khadjavi A, Giribaldi G, Prato M: Haemozoin induces early cytokine-mediated lysozyme release from human monocytes through p38 MAPK- and NF-kappaB-dependent mechanisms. PLoS One 2012, 7:e39497.

39. Thuno M, Macho B, Eugen-Olsen J: suPAR: the molecular crystal ball. Dis Markers 2009, 27:157-172.

40. Endre ZH, Pickering JW: Biomarkers and creatinine in AKI: the trough of disillusionment or the slope of enlightenment? Kidney Int/ 2013, 84:644-647.

doi:10.1186/1475-2875-13-91

Cite this article as: Plewes et al:: Correlation of biomarkers for parasite burden and immune activation with acute kidney injury in severe falciparum malaria. Malaria Journal 2014 13:91.

\section{Submit your next manuscript to BioMed Central and take full advantage of:}

- Convenient online submission

- Thorough peer review

- No space constraints or color figure charges

- Immediate publication on acceptance

- Inclusion in PubMed, CAS, Scopus and Google Scholar

- Research which is freely available for redistribution 